\title{
Crítica da inspiração nos processos comunicacionais do capitalismo cool$^{1}$ Critique of inspiration in the communications processes of cool capitalism
}

Vander Casaqui ${ }^{2}$

Resumo: Este artigo tem como objetivo tratar da inspiração, como elemento que identifica os processos comunicacionais relacionados com a cultura empreendedora. Nesse sentido, a publicização dos ideais, valores, prescrições dos agentes identificados com o empreendedorismo parte de um modelo comunicacional bem delimitado, cuja função principal é inspirar, ou seja, transformar o outro, que compõe seu auditório social (BAKHTIN, 1997). Essa transformação desejada seria, em última instância, a promoção do engajamento no capitalismo contemporâneo em sua face mais sedutora, que McGuigan (2009) define como cool capitalism. Em síntese, procuramos discutir as intersecções entre inspiração, empreendedorismo e o capitalismo neoliberal, ou sociedade neoliberal (conforme DARDOT; LAVAL, 2016).

Palavras-chave: comunicação e consumo; cultura empreendedora; discurso social; inspiração; sociedade neoliberal.

Abstract: This article aims to deal with inspiration as an element that identifies the communicational processes related to the entrepreneurial culture. In this sense, the publicity of the ideals, values, prescriptions of agents identified with entrepreneurship starts from a well-delimited communicational model whose

1 Versão modificada, atualizada e expandida de trabalho apresentado no GP Publicidade e Propaganda do XVI Encontro dos Grupos de Pesquisa em Comunicação, evento componente do XXXIX INTERCOM - Congresso Brasileiro de Ciências da Comunicação, realizado em setembro de 2016.

Pesquisa financiada com Auxílio à Pesquisa FAPESP - processo n. 2019/14365-7.

2 Universidade Metodista de São Paulo (UMESP). São Paulo, SP, Brasil.

https://orcid.org/0000-0001-7823-9861.E-mail: vander_casaqui@yahoo.com.br 
main function is to inspire, that is, to transform the other, that composes its social auditorium (BAKHTIN, 1997). This desired transformation would ultimately be the promotion of engagement in contemporary capitalism in its most seductive face, which McGuigan (2009) defines as cool capitalism. In summary, we try to discuss the intersections between inspiration, entrepreneurship and neoliberal capitalism, or neoliberal society (according to DARDOT; LAVAL, 2016).

Keywords: communication and consumption; entrepreneurial culture; social discourse; inspiration; neoliberal society. 


\section{Introdução}

A inspiração se tornou um termo recorrente em nosso tempo. Sua presença é tão frequente, e ao mesmo tempo tão banalizada, que temos a impressão de que todo mundo pensa em si mesmo como uma possível narrativa inspiracional, como uma trajetória de vida a ser replicada pelo outro. O compartilhamento na mídia digital de frases emblemáticas, de imagens emocionantes, de exemplos de gestos humanos dos mais diversos, em comunidades como o Facebook, é outra face dessa verdadeira cultura da inspiração. Diante dessa miríade de discursos que assumem o objetivo de inspirar, as perguntas a serem respondidas no âmbito deste trabalho são: como compreender a inspiração como expressão da cultura empreendedora de nosso tempo? Qual o papel da inspiração na disseminação da ideologia do neoliberalismo? Como o ato de inspirar se molda a modelos comunicacionais bem delimitados, tomando parte de estratégias de agentes identificados com o campo do empreendedorismo? Para o desenvolvimento desse estudo, nos apoiamos nos preceitos teórico-metodológicos do discurso social, propostos por Marc Angenot (2010): de acordo com o autor, os discursos podem constituir hegemonias, quando se configuram como um paradigma demarcado em termos sociais, culturais e históricos. Ou seja: o discurso social corresponde ao horizonte do que é pensável, dizível em dado momento histórico, e se concretiza em certas regularidades discursivas, em certos padrões que são repetidos, atualizados, mas que mantêm uma identidade em relação a essa hegemonia.

A concepção do discurso social é interdependente da perspectiva dialógica da linguagem, no sentido bakhtiniano. Dessa forma, "ao construir discursos que explicam, organizam e classificam o mundo, o locutor estabelece relações e dependências, expressa valores e visões de mundo, dialoga com enunciados anteriores e posteriores" (PISTORI; BANKS-LEITE, 2010, p. 131). Nesse processo social de interação é que se constituem o locutor e o seu interlocutor. $\mathrm{O}$ auditório social é esse outro projetado a partir da enunciação; o dizível e o pensável são demarcados historicamente, e essa delimitação corresponde ao auditório 
social imaginado no contexto em que os enunciados se estabelecem dialogicamente. Os agentes da cultura empreendedora e seus discursos, que caracterizam nosso objeto de pesquisa, evidenciam esse processo interacional da linguagem, ao conceberem a si próprios como seres inspiradores e ao seu auditório social como um conjunto de indivíduos a serem inspirados. Para esse estudo, selecionamos expoentes notórios da cultura da inspiração no Brasil contemporâneo, que tanto representam agentes que constituem suas narrativas biográficas em chave motivacional, quanto demonstram institucionalidades que estabelecem como missão organizacional o objetivo de inspirar. Essa diversidade de casos está a serviço do objetivo de evidenciar a amplitude e as nuances correspondentes ao estudo da cultura da inspiração, em sua relação com o espírito do capitalismo contemporâneo.

Em um cenário de flexibilização e precarização do trabalho, como aponta Sennett (2007), como vivemos atualmente, em tons dramáticos, especialmente nas economias em desenvolvimento - como é o cenário latino-americano -, emergem simultaneamente os discursos que promovem e positivam a cultura empreendedora, como antídoto a esse estado de coisas. Dessa forma, diante de uma situação de desemprego, de desamparo em relação às políticas sociais de Estado, de crise em sentido amplo, essa cultura se coloca como solução que, em última instância, atribui ao indivíduo a responsabilidade por transformar o próprio destino, o fracasso em sucesso, a atitude de sujeito "comum" em atitude empreendedora. A proposta de análise crítica do discurso social de Angenot, mais do que uma metodologia com procedimentos bem delineados, é aplicada nesta pesquisa como a análise do espírito do tempo concretizado em teias discursivas complexas, que correspondem a um momento histórico e a uma sociedade específicos. Este trabalho entende o empreendedorismo como discurso social, e procura identificar a amplitude e a difusão de seus preceitos pela tomada de voz de uma multiplicidade de agentes que falam em nome da cultura empreendedora - simultaneamente atualizando-a e reiterando sua ideologia. 
No decorrer de nossa pesquisa sobre o empreendedorismo social e sobre a cultura empreendedora, a partir dos objetos que estudamos, encontramos inúmeras vezes o uso do termo inspiração, que, em nossa leitura, representa a face mais sedutora do capitalismo "cool", como define McGuigan (2009). O conceito de capitalismo cool é baseado na capacidade de "absorção do desafeto no próprio capitalismo" (MCGUIGAN, 2013, p. 13). Segundo o autor, esse processo de absorção caracteriza o papel do "cool", voltado a "transformar o desafeto em aceitação e consentimento” (idem, p. 14). Uma forma mais densa de compreensão desse processo está baseada na teoria do novo espírito do capitalismo de Boltanski e Chiapello (2009), que destaca a capacidade do sistema capitalista de se repropor como nova retórica, ciclicamente, a partir da incorporação dos argumentos e embates promovidos por seus críticos. Dessa forma, se o enfrentamento juvenil da geração de maio de 68 levantava bandeiras antissistema, imaginando "um outro mundo possível”, hoje encontramos o discurso revolucionário, de transformação do mundo, de autonomia e liberdade, incorporados no interior do próprio sistema capitalista, a partir dos significados atribuídos à atividade empreendedora, ao empreendedorismo social, entre outras vertentes que são interdependentes do modo de operação do mercado neoliberal.

Nesse espectro, a "aceitação e consentimento" descritos por McGuigan são entendidos, por Boltanski e Chiapello, como formas de promover engajamento dos sujeitos no sistema capitalista, especialmente os mais jovens, que vão renovar seus quadros e cuidar de seu futuro. Sendo assim, o projeto de sociedade empreendedora defendido por autores como Drucker (2011) propõe, em tese, um "mesmo mundo possível”, uma ideologia ao mesmo tempo reformista e preservacionista dos princípios do capitalismo, rechaçando toda e qualquer forma revolucionária de transformação social. O sujeito modelar desse projeto é uma versão atualizada do destruidor criativo, discutido por Schumpeter (1942); o espírito empreendedor independe da concepção de um empreendimento no sentido clássico, de gerar um novo negócio, de transformar um mercado por meio de um produto ou serviço inovador. A atitude empreendedora 
- as características psicológicas e morais atribuídas a esse sujeito -, sobrepõe-se à sua habilitação técnica para realizar um empreendimento. Diante de um cenário social que Sennett (2007) define como capitalismo flexível, em que os sujeitos estariam à deriva diante das mudanças constantes, dos riscos contínuos, da flexibilidade como exigência primordial e como modelo paradigmático para o mundo do trabalho, dos fluxos de curto prazo, dos valores efêmeros, “a instabilidade pretende ser normal, o empresário de Schumpeter aparecendo como o Homem Comum Ideal" (SENNETT, 2007, p. 33).

O principal empreendimento em nosso tempo é conceber a própria vida como algo a ser gerenciado, otimizado, performatizado, em compatibilidade com o cenário dinâmico, flexível e competitivo, como bem aponta o Blog Geração de Valor, um dos agentes dessa cultura da inspiração que atua no Brasil. Em uma de suas publicações que mais evidenciam esse cenário, temos a imagem em close de um casal, homem e mulher, mirando-se, olhos nos olhos, caracterizando um momento romântico, iluminado pelos reflexos da luz solar. A imagem afetiva do par é ressignificada pela sobreposição de uma frase, uma máxima assinada acompanhada pelo logotipo do blog: "Sua vida, seu maior empreendimento". Dessa forma, os próprios relacionamentos amorosos são passíveis de gerenciamento. Illouz (2009), ao tratar da utopia romântica no contexto contemporâneo, explicita a relação dessa utopia com a cultura gerencial correspondente ao capitalismo neoliberal. $\mathrm{O}$ casamento bem-sucedido, por exemplo, é um ideal propagado na sociedade, que corresponde a um mercado bastante vigoroso, ou seja, promove o consumo e mobiliza uma série de agentes que trabalham em função dessa utopia, tornada mercadoria. O casamento também é uma empresa, uma vez que os sujeitos envolvidos na relação podem utilizar a sua inteligência emocional, definir metas, procedimentos, promover a divisão social do trabalho na própria casa para atingirem seus objetivos de felicidade. Essas medidas e procedimentos, propagadas por gurus, coachs especializados no tema, são derivados diretamente da cultura gerencial que constitui uma hegemonia articulada ao capitalismo de nosso 
tempo. O sonho, no âmbito do capitalismo cool, serve como forma de engajamento no sistema, num sentido de totalidade: nenhuma faceta da existência parece escapar à possibilidade de ser gerenciável, administrável, planejada e executada nos termos da racionalidade promovida pelo sistema.

Mas, enfim, como entendemos a noção de capitalismo cool no âmbito deste trabalho? Identificamos que a linha de frente desse sistema na contemporaneidade está baseada nos discursos que, derivados de uma estética publicitária, publicizam o sonho, estimulam a autonomia, a liberdade, a força motivacional para mudar o mundo, associando essas forças motrizes com a atividade empreendedora. A produção de narrativas inspiracionais se concebe, nesse espectro, como uma economia e como um mercado. A noção de economia, etimologicamente, está baseada na administração, na gestão. Entendemos o mercado como dinâmica do sistema capitalista, em que a forma - mercadoria é central para a cadeia de produção - circulação - consumo. Dessa forma, a produção de narrativas inspiracionais que interessa a esse estudo se baseia nessa lógica capitalista de gestão e da produção de mercadorias, bem como na inserção dessa produção em um mercado de ideias (ANGENOT, 2010). São diversos os agentes que disputam simbolicamente o poder de inspirar: grandes corporações e suas comunicações publicitárias; agentes capitalistas que personalizam e dão voz ao sistema em fóruns mundiais e outros eventos globalizados, transmitidos online para audiências maciças ao redor do mundo; palestrantes que encontraram na atividade de inspiração uma forma de produzir lucro e notoriedade; ativistas e "mobilizadores" (para usar o jargão corrente nesse meio) ligados ao campo do empreendedorismo e do empreendedorismo social.

\section{A cultura empreendedora contemporânea e as narrativas inspiracionais}

Como apontamos anteriormente, a noção de empreendedorismo se dissemina em nossos dias, tornando-se a panaceia de nosso tempo, ou 
seja, a cura de todos os males, a solução de qualquer problema, no âmbito macro ao microssocial, da falência do Estado à vida interior dos indivíduos. É preciso frisar: essa é a macroproposição (VAN DIJK, 1978, p. 62-63) derivada da cultura empreendedora, que é defendida e divulgada por uma gama bastante diversa de agentes. Dessa forma, a abordagem comunicacional do empreendedorismo que corresponde ao nosso estudo escapa a uma visão restrita do empreendedor, como um agente econômico que concebe um negócio, que desenvolve um projeto, uma mercadoria, que produz inovação para atender e transformar as demandas do mercado. Entendemos que, sob a noção ampliada da cultura empreendedora, que é publicizada por suportes midiáticos, os indivíduos de nosso tempo são convocados a serem empreendedores de si mesmos, em qualquer esfera da vida cotidiana. É essa perspectiva do empreendedor, como signo construído midiaticamente, que se conecta com a cultura da inspiração. No âmbito deste trabalho, o empreendedorismo é tratado em perspectiva crítica, ou seja, é visto em suas tramas discursivas como um tema a ser desconstruído, observado com distanciamento, discutido à luz das teorias sociais, que problematizam as questões do mundo do trabalho, os sentidos do empreendedorismo e seus desdobramentos na vida cotidiana.

"Eu tenho visto muitas entrevistas e matérias sobre empreendedores na mídia em geral". Essa afirmação, com a qual concordaram 56\% dos entrevistados na pesquisa da Endeavor Brasil, intitulada "Cultura empreendedora no Brasil" (ENDEAVOR, 2014, p. 9), oferece pistas para compreender que o empreendedorismo é um tema onipresente em nosso tempo. O "espírito empreendedor" se tornou um traço comportamental positivo de qualquer trabalhador, quando consideramos os modelos ideais difundidos atualmente. Sua presença midiática, bem como sua percepção como algo recorrente no cotidiano, são sintomas de um problema de delimitação do que significa empreender atualmente. Como diz Foucault (2008), o empreendedor é também um empreendedor de si mesmo; para além do clássico self-made man, o modelo mítico da cultura norte-americana, o empreendedor de si é o sujeito que incorpora as 
convocações biopolíticas (PRADO, 2013) para transformar-se continuamente, para ser um gestor eficaz de seu capital humano. Um exemplo recente dessa perspectiva de ver a si mesmo como empreendimento, que implica um processo de autotransformação, é a produção discursiva de Bel Pesce, que se tornou uma celebridade empreendedora, principalmente por conta de seus livros, que combinam autobiografia e lições sobre como empreender em todos os aspectos da vida. Suas obras são identificadas como inspiracionais, como defende Flávio Augusto da Silva, criador do Instituto Geração de Valor (que, entre outras coisas, é responsável por um blog motivacional, que tem o objetivo de inspirar pessoas), em seu prefácio do livro de Bel Pesce, o best-seller A menina do vale (PESCE, 2015a). O texto de Flávio Augusto, intitulado "A realidade que inspira", diz que:

A história de Bel não é uma ficção. É uma história real que pode inspirálo a protagonizar seu próprio roteiro. As experiências no Vale do Silício aqui descritas poderão servir de matéria-prima para a construção de ideias a fim de lhe encorajar a seguir adiante com garra, acreditando ainda mais em seu futuro (SILVA, 2015, p.13-14, grifo nosso).

Na citação acima, identificamos uma série de ideias que discutimos até o momento. A produção de narrativas com o objetivo de inspirar, de gerar uma nova trajetória de vida no outro, no caso, o jovem brasileiro, a ser engajado a partir do modelo do Vale do Silício - a Meca do capitalismo mais exuberante de nosso tempo, associado às novas tecnologias, à efervescência inovadora, à concepção de negócios milionários e mercadorias tão sedutoras quanto materializadoras de ideais de futuro, resumidos aos processos de consumo. E, como síntese, o paralelismo entre trajetória de vida e aventura empreendedora, como fica explícito nas palavras de Bel Pesce: "Tenho plena consciência de que ainda há muito mais a aprender e de que estarei nessa aventura empreendedora por anos e anos à frente" (PESCE, 2015a, p. 25, grifo nosso). A trajetória de Bel Pesce, para além de sua autobiografia, demonstra as fragilidades da narrativização da vida, que alça seres "comuns" à dimensão heroica. A "Menina do Vale", que surgiu como celebridade empreendedora, por 
ocupar espaços na mídia para contar sua história de sucesso no Vale do Silício e reiterar sua condição de garota prodígio - autorizada para assumir o discurso competente sobre empreendedorismo e a gestão do próprio capital humano - foi confrontada com a desconstrução de seus "feitos" narrados e sofreu duras críticas nas redes sociais. A evidência desse choque entre a narrativa heroica e a apuração dos fatos está registrada na cobertura do site de notícias e variedades UOL: Pesce, em 2012, contou sua história em duas entrevistas feitas pelo site. Em 2016, vieram à tona as inconsistências de seu relato, que foi corrigido por erratas, como se pode ver no trecho:

A empreendedora Bel Pesce tem duas graduações no MIT, e não cinco. Ela se formou em "administração" e "engenharia elétrica e ciências da computação" (este último é um curso só, e não dois, como dava a entender). [...] Ela não foi a única nem a principal fundadora da empresa dos EUA Lemon (aplicativo de finanças pessoais), como dava a entender a reportagem. Ela foi membro da equipe fundadora, à qual se juntou pouco depois de formada a equipe original. (GAMA, 2016).

Em sua obra de 2015, A sua melhor versão te leva além (PESCE, 2015b), a autora compartilha suas técnicas para desenvolver uma versão melhor de si a cada dia. Nas palavras de Bel Pesce: "grandes transformações são totalmente aceitáveis se te levarem mais perto de fazer o seu melhor e ser a sua melhor versão" (p. 76). Empreender a si mesmo, nesse cenário, representa uma forma de convocação biopolítica, em que o corpo e a mente devem ser passíveis da gestão para um melhor desempenho, de forma contínua, sem linha de chegada. Estamos no território do culto à performance, como define Ehrenberg (2010). Byung-Chul Han, em diálogo com as ideias de Foucault (sociedade de controle) e de Ehrenberg, problematiza o sujeito do desempenho, que

(...) está livre da instância externa de domínio que o obriga a trabalhar ou que poderia explorá-lo. É senhor e soberano de si mesmo. Assim, não está submisso a ninguém ou está submisso apenas a si mesmo. É nisso que ele se distingue do sujeito da obediência. (BYUNG-CHUL, 2015, p. 29-30). 
Observemos como essa convocação biopolítica (PRADO, 2013) do sujeito do desempenho se traduz numa forma comunicativa em chave motivacional, em outra comunicação do já citado blog Geração de Valor com o título "A inspiração é o que faz a sua transpiração valer a pena", o banner traz a imagem de uma mulher, vista em tomada em plongée, ou seja, de cima para baixo, escalando uma montanha e tendo ao fundo um vale, que representa o risco da queda, do fracasso, enfim. No entanto, a expressão da mulher é de superação do desafio, da escalada bem-sucedida ao topo. O sucesso ali representado é identificado com a resiliência, com a perseverança - atributos identificados de forma recorrente à imagem paradigmática do empreendedor, e que na comunicação do blog são sintetizados pela palavra "transpiração".

A relação entre inspiração e transpiração, apresentada normalmente no senso comum sobre o processo criativo - que, em última instância, valoriza os "95\% de transpiração" e não os "5\% de inspiração", ou o trabalho árduo em contraponto à criação com contornos artísticos - aqui é revista para dar ênfase à inspiração como guia, como iluminação a ser materializada pelo esforço da transpiração; sem inspiração, o esforço seria inútil. A imagem do esportista, que escala uma montanha e supera riscos para chegar ao cume, é um clichê, uma alegoria óbvia da alta performance, da superação contínua e sem limites do sujeito do desempenho. Esse recurso de mobilizar já ditos, imagens e ideias bastante codificados na cultura tanto serve como reafirmação do que está naturalizado em dado contexto, ganhando uma "aura" de verdade, quanto se apoia, em termos comunicacionais, na identificação e na familiaridade da audiência com esse dizer, como estratégia retórica para produzir afetos - para, enfim, inspirar. Mas que inspiração seria essa capaz de municiar o sujeito do desempenho? Talvez o modelo a promover e dar sentido à inspiração promovida pelo banner esteja colocado no próprio blog, quando o seu idealizador, Flávio Augusto, oferece sua trajetória de vida como inspiradora. Diz o texto de apresentação do podcast sobre a biografia de Flávio Augusto: "Reconhecido várias vezes como um dos líderes mais inspiradores e admirados pelos jovens brasileiros, Flávio 
Augusto da Silva tem uma trajetória bastante conhecida. Seus passos, seus desafios, suas histórias. Mas será que você já conhece tudo?”.

Flávio Augusto, por meio de seu blog Geração de Valor, projeta sua narrativa de vida como modelar, como líder de uma geração, o exemplo do sucesso a ser seguido, o modelo para os aspirantes a sujeitos de alta performance. Empresário bem-sucedido, dono de uma rede de escolas de línguas, a Wise Up, seu sucesso só pode ser compreendido no paradigma do mercado capitalista, ou seja, a partir dos lucros obtidos, da participação significativa em um mercado concorrido, dos resultados quantificados como forma de legitimar o valor das conquistas. No entanto, sua atuação a partir do blog o projeta como líder inspirador e visionário, como alguém que seria traduzido por uma narrativa de vida exemplar, de acordo com as ideias de Buonanno (2011). Não à toa, Bel Pesce e Flávio Augusto foram identificados como expoentes da cultura empreendedora no Brasil em tempos recentes, por sua entrada na cena midiática, por terem se tornado celebridades empreendedoras, ou empreendedores-celebridades.

\section{A positividade dos modelos comunicacionais baseados na inspiração}

Como discutimos anteriormente, a inspiração, no contexto da cultura empreendedora, tem relação direta com modelos comunicacionais projetados por seus agentes, em suas estratégias - o que muitas vezes configura a maneira como se desenha o negócio, o empreendimento. A observação desse aspecto nos permite problematizar alguns aspectos relacionados ao empreendedorismo como objeto do campo da comunicação, bem como permite avançar na compreensão dos projetos de sociedade em jogo nessa cena.

O modelo mais simples, e mais frequente, é o que discutimos até o momento, pelos exemplos das narrativas de vida inspiracionais: o espaço biográfico, que, de acordo com Arfuch (2010), engloba tanto biografias quanto autobiografias, nesta pesquisa tem como pressuposto a produção 
da vida como narrativa em chave motivacional. Essa produção, por sua vez, está inserida na cadeia que também inclui a circulação e o consumo dessas mensagens. Ou seja, os agentes que assumem o lugar dessa produção estabelecem para si a missão de propagar uma mensagem, de disseminar a "boa nova": tanto no caso de Bel Pesce quanto no de Flávio Augusto, trata-se de uma espécie de evangelização, para utilizarmos um termo que é recorrente nos eventos promovidos pelo Google ao redor do mundo. Em sua obra A corrosão do caráter (2007), Sennett discute os paradoxos gerados pelo contexto do capitalismo flexível, que resulta, entre outras coisas, num conflito essencialmente de produção narrativa de cada sujeito. Como diz Sennett, "o problema que enfrentamos é como organizar as histórias de nossa vida agora, num capitalismo que nos deixa à deriva" (2007, p. 140).

O cenário anterior, de um capitalismo que alimentava a noção de carreira, de continuidade, de certa estabilidade, por mais que promovesse a exploração da força de trabalho no sentido clássico (como aborda a teoria marxista), em contrapartida oferecia ao trabalhador a possibilidade de constituir uma narrativa identitária coerente, construída ao longo do tempo, o que tem implicações diretas com a formação do caráter: "o termo caráter concentra-se sobretudo no aspecto a longo prazo de nossa experiência emocional. (...) Caráter são os traços pessoais a que damos valor em nós mesmos, e pelos quais buscamos que os outros nos valorizem" (SENNETT, 2007, p. 10). A corrosão do caráter corresponde à fragmentação do tempo narrativo no capitalismo flexível, à deriva dos sujeitos diante do imperativo "não há longo prazo", da mudança contínua, da descontinuidade e do distanciamento dos laços laborais. As dificuldades apresentadas a partir do personagem Rico, presente no livro de Sennett, demonstram que os impedimentos de uma produção narrativa satisfatória, baseada em laços fortes, produzem consequências na vida emocional, principalmente nas transposições da ética do trabalho para a ética familiar, ou, de maneira mais ampla, para a vida cotidiana, para além da atividade laboral. 
A busca da cura da narrativa, da solução para esse impasse, parece resultar no ato de voltar para a sua própria interioridade, de encontrar em si mesmo o sentido da coerência. No âmbito da cultura da inspiração, isso passa pela incorporação de modelos narrativos a seguir, das histórias de vida exemplares a replicar em nossas vidas. Em última instância, esse é um processo de produção e consumo de narrativas, que implica transformação do sujeito consumidor para se adequar ao modelo de sucesso. Nesse ponto, o empreendedorismo e o mercado da autoajuda, no sentido de Illouz (2011), estão alinhados. A tarefa de empreender a si mesmo pode ser desencadeada pela inspiração gerada pela história do outro, que traz algo de coerente, de heroico, de épico, baseado na força interior que se sobrepõe aos obstáculos do mundo, quaisquer que sejam - basta haver vontade e fé para a superação. Há algo de místico, tanto mágico quanto terapêutico, nesse processo comunicativo da inspiração, no espectro do empreendedorismo de si mesmo.

De acordo com Gallouj, na apresentação do curioso Journal of Inspiration Economy, editado pela University of Bahrain desde 2014, a inspiração é um fenômeno complexo, difícil de definir, que "descreve uma dinâmica psicológica particular, um estalo criativo casual” (2014, p. 4, tradução nossa), entre outros significados usualmente atribuídos ao termo. O autor aponta que, etimologicamente, o termo está baseado no latim "in spiritum”, que significa "ter o Espírito (quer dizer, Deus) em você” (Gallouj, 2014); essa noção tem correspondência com o entendimento da inspiração na Grécia Antiga, onde os artistas eram inspirados pelas Musas, filhas de Zeus e Mnemosine.

Gallouj (2014) discute as relações entre a tradição artística e religiosa da noção de inspiração, e seus usos na esfera econômica. Ao passo que a primeira tradição tem uma natureza transcendente, a economia da inspiração é de caráter relacional, interacional, em que os níveis individuais, corporativos, municipais, regionais, nacional de dada sociedade são articulados em "recíprocas relações de inspiração" (2014, p. 5, tradução nossa). Nesse sentido, "mesmo num ambiente competitivo, os produtores inspiram uns aos outros, os consumidores inspiram 
os produtores e vice-versa" (Gallouj, 2014). Essa visão mercadológica da inspiração, no entanto, necessita de um contraponto crítico, uma vez que as relações competitivas promovidas pelo neoliberalismo, ou mesmo as relações entre produtores e consumidores, não são tão harmônicas como nesse desenho de um ecossistema de múltiplas inspirações, de lado a lado. A dimensão relacional da inspiração, ou a economia da inspiração, de acordo com a visão de Gallouj, corresponde, em nossa leitura, ao desenho da sociedade positiva, que é abordada criticamente por Byung-Chul Han (2013, p. 11-12, tradução nossa):

As coisas se tornam transparentes quando abandonam qualquer negatividade, quando se alisam e se aplainam, quando são inseridas sem resistência no fluxo suave do capital, a comunicação e a informação. As ações se tornam transparentes quando se fazem operacionais, quando são submetidas aos processos de cálculo, gestão e controle.

Nesse cenário, alerta o autor, a negatividade, a resistência do outro, o estranho a esses fluxos, gera a perturbação da "lisa comunicação do igual” (Gallouj, 2014). A comunicação identificada com a sociedade positiva, por outro lado, "estabiliza e acelera o sistema, pelo fato de eliminar o outro, o estranho” (Gallouj, 2014). Nesse aspecto, há uma coação sistêmica, que promove uma sociedade uniformizada. Essa é a expressão de uma monocultura empreendedora, o projeto ideal dos agentes mais combativos dessa cena.

O modelo comunicacional da Endeavor, organização global que incentiva o empreendedorismo, e que conta com uma filial no Brasil, representa seu sistema produtivo e as cadeias que derivam de sua atividade, num processo sintetizado pela frase: "acreditamos que a força do exemplo é o caminho para multiplicar empreendedores que transformam o Brasil”. No modelo gráfico que representa a sua atuação, a sua "missão", a Endeavor estabelece dois fins básicos: "inspirar e capacitar os atuais e futuros empreendedores" e "provocar mudanças no ambiente empreendedor”, com vistas à construção de um Brasil empreendedor - identificado pelo mapa do país preenchido pela imagem estilizada e padronizada de homens, ladeados, associados ao termo empreendedor. 
"Inspirar e capacitar" é um objetivo resultante da atividade de compartilhamento de "histórias e aprendizados práticos" de empreendedores de alto impacto, que "trocam conhecimento" com os mentores da rede Endeavor - os mediadores desse saber prático que deve ser replicado para cumprir a missão de inspirar e capacitar novos empreendedores associados ao mundo construído pela organização. Por outro lado, o estímulo às mudanças é baseado na "visão de quem está na linha de frente do empreendedorismo"; a adesão à ideologia empreendedora é evidente, bem como a visão hierárquica, "de cima para baixo", ou seja, dos líderes de um campo, daqueles empreendedores bem-sucedidos alinhados com o projeto de sociedade empreendedora capitaneado pela Endeavor.

Aparentemente mais complexo que o modelo de produção de narrativas inspiracionais de agentes individuais e seus efeitos ambicionados, o gráfico da Endeavor reitera esse modelo unidirecional, com vistas à construção de um Brasil empreendedor. A Endeavor compartilha "histórias e aprendizados práticos" para inspirar e capacitar empreendedores; do universo de empreendedores brasileiros, implicitamente produzidos por sua ação, seleciona e "potencializa" aqueles que serão reconhecidos como "empreendedores de alto impacto" - novos líderes inspiradores, que terão suas histórias compartilhadas para inspirar futuros empreendedores. Ao mesmo tempo, esse corpo de notáveis, de sujeitos de alta performance, são posicionados como mentores na linha de frente da ação de "provocar mudanças no ambiente empreendedor". Sendo assim, "inspirar e capacitar" por um lado, e "provocar mudanças" por outro, são ações com um objetivo comum: produzir uma sociedade empreendedora, uma nação de empreendedores que se alinham aos fluxos e lógicas da sociedade positiva, conforme problematiza Byung-Chul (2013). A rede Endeavor, representada na imagem dos homens ao centro do gráfico, configura uma hierarquia, baseada na centralidade do empreendedor de alto impacto - que é demonstrado visualmente como irradiador e como líder legítimo de uma "nova economia", baseada na utopia pragmática da sociedade empreendedora. 
124 CRÍTICA DA INSPIRAÇÃO NOS PROCESSOS COMUNICACIONAIS DO CAPITALISMO COOL

\section{Considerações finais}

$\mathrm{Na}$ (in)conclusão deste artigo, retomamos os três questionamentos lançados no início, a fim de, mesmo que parcialmente, respondê-los. Em relação ao primeiro (como compreender a inspiração como expressão da cultura empreendedora de nosso tempo?), procuramos discutir como a inspiração, no contexto atual, corresponde a estratégias comunicacionais que interpelam os sujeitos, como forma de convocação biopolítica, para que se transformem continuamente, sejam sempre mais sujeitos do desempenho, gestores eficazes de si mesmos.

Buonanno (2011), ao discutir sobre o fenômeno contemporâneo da profusão de heróis de todos os dias, ou seja, da possibilidade de qualquer um se reconhecer e ser reconhecido como tal, conclui que numa era em que todos podem ser heróis, ninguém efetivamente é herói. Em nosso estudo, identificamos que os heróis de nosso tempo são sujeitos capazes de produzir a si mesmos como narrativas inspiradoras. Num mundo onde todo mundo pode ser inspirador, há dúvidas sobre quem inspira quem, quem é inspirador e quem efetivamente é inspirado. Bel Pesce e Flávio Augusto são exemplos desse processo da produção de si como líder inspirador, mobilizador, transformador, entre outras denominações atribuídas a esses sujeitos modelares da cultura empreendedora. Eis um mercado que, analisado criticamente, tem muito a dizer sobre o espírito do tempo.

Sobre a segunda questão (qual o papel da inspiração na disseminação da ideologia do neoliberalismo?), podemos afirmar que a ideologia neoliberal permeia todo o fenômeno da inspiração, no recorte delimitado por esse estudo. A noção de capitalismo "cool" corresponde à forma sedutora com que as lógicas dessa ideologia são transmitidas, como mensagens inspiradoras. A lógica da concorrência, a transformação do sujeito em empreendimento, a vida como objeto da gestão, os modelos de negócios aplicados a processos comunicacionais, e, principalmente, o projeto de sociedade empreendedora materializado pelos exemplos analisados - todos esses elementos são publicizados, por meio da estratégia comunicacional da inspiração. O capitalismo contemporâneo sonha, inspira, 
mobiliza, transforma - e quando produz lucro, soma a ele o propósito, que é a expressão-coringa do idealismo que redime o capitalista de sua ambição de reprodução ilimitada do capital. A concepção do empreendedorismo como discurso social (ANGENOT, 2010) é a tradução e atualização dos preceitos capitalistas a um universo de possibilidades de transformação abertas pelos meios técnicos disponíveis, como as redes digitais, mas que vivem esse movimento ambíguo de representar a expansão do sistema para a gestão das mentalidades. As plataformas digitais, que são o suporte para diversos discursos aqui analisados e tantos outros, têm se configurado como um braço simbólico importante para a difusão dos ideais e imperativos neoliberais.

Por fim, tratamos da terceira questão (como o ato de inspirar se molda a modelos comunicacionais bem delimitados, tomando parte de estratégias de agentes identificados com o campo do empreendedorismo?). Por meio de duas categorias de exemplos, os agentes empreendedores individuais (Bel Pesce e Flávio Augusto) e o agente corporativo (representado pela Endeavor Brasil), discutimos como o trabalho de ambos se baseia em processos comunicacionais, em que a inspiração é o efeito produzido por suas ações e discursos. Dessa forma, há uma estratégia implícita de autolegitimação, de produção do próprio agente como líder de uma sociedade supostamente utópica, que ele imagina ser a melhor para o futuro de todos - a expressão do "bem comum", o resultado dos esforços e da devoção da "gente de bem".

O capitalismo "cool" é a face sedutora de um projeto de sociedade positiva em que o outro, o estranho, aquele que atrapalha os acelerados fluxos comunicacionais, estabelecidos entre iguais, sem ruídos previstos, deve ser excluído. A teia social baseada na rede de inspirações mútuas, como defende Galouj (2014), é uma leitura fundada nessa versão positiva do mundo. Uma leitura derivada do projeto de sociedade empreendedora, que, apesar de se autoproclamar defensora do bem comum, parece ter acima desse ideal abstrato o objetivo de construir um mundo baseado no pensamento único. Uma monocultura empreendedora - que, obviamente, exclui de seus fluxos comunicacionais aqueles 
que não se ajustam a seus modelos. A ideia da diversidade cultural, do princípio democrático no sentido mais profundo, faz-se absolutamente necessária para problematizar esses projetos de sociedade, para além de sua face "cool", inspiradora e motivacional. Diante dos princípios da sociedade positiva, o negativismo é a perspectiva crítica necessária para se repensar o humanismo, em tempos da cultura empreendedora.

\section{Referências}

ANGENOT, M. El discurso social: los limites históricos de lo pensable y lo decible. Buenos Aires: Siglo XXI, 2010.

ARFUCH, L. O espaço biográfico: dilemas da subjetividade contemporânea. Rio de Janeiro: EdUERJ, 2010.

BAKHTIN, M. (Voloshinov). Marxismo e filosofia da linguagem. São Paulo: Hucitec, 1997.

BOLTANSKI, L.; CHIAPELLO, È. O novo espírito do capitalismo. São Paulo: Martins Fontes, 2009.

BUONANNO, M. Histórias de vida exemplares. Biografias. MATRIZes, ano 5, n. 1, p. 63-84, 2011.

BYUNG-CHUL, H. Sociedade do cansaço. Petrópolis, RJ: Vozes, 2015.

La sociedad de la transparencia. Herder Editorial: Barcelona, 2013.

DARDOT, P.; LAVAL, C. A nova razão do mundo: ensaio sobre a sociedade neoliberal. São Paulo: Boitempo, 2016.

DRUCKER, P. F. Inovação e espírito empreendedor: prática e princípios. São Paulo: Cengage Learning, 2011.

ENDEAVOR. Cultura empreendedora no Brasil, 2014. Disponível em: http://info.endeavor.org.br/os-perfis-dos-empreendedores-brasileiros. Acesso em: 11 abr. 2019.

EHRENBERG, A. O culto da performance: da aventura empreendedora à depressão nervosa. Aparecida - SP: Idéias \& Letras, 2010.

FOUCAULT, M. Birth of biopolitics. New York: Palgrave Macmillan, 2008.

GALOUJ, F. "Inspiration Economy": A New Journal. Journal of Inspiration Economy: an International Journal, vol. 1, issue 1, sept 2014, p. 7-13. Disponível em: http://journals.uob.edu.bh/JIE/contents/volume-39/articles/article-838. Acesso em: 15 ago. 2018.

GAMA, R. Empreendedora Bel Pesce dá 10 dicas para sucesso na carreira. UOL, São Paulo, 1 jun. 2012 - atualizada em 5 set, 2016. Disponivel em: https:/economia.uol. com.br/noticias/redacao/2012/06/01/talento-brasileiro-nos-eua-bel-pesce-da-10-dicas-para-empreender-com-sucesso.htm. Acesso em: 18 nov. 2019.

ILLOUZ, E. O amor nos tempos do capitalismo. Rio de Janeiro: Zahar, 2011.

El consumo de la utopía romántica: el amor y las contradicciones culturales del capitalismo. Espanha: Katz, 2009. 
MCGUIGAN, J. Do populismo cultural ao capitalismo legal. Revista Contracampo, $v$. 28, n. 3, dez.-mar. Niterói: Contracampo, p. 5-25, 2013.

. Cool capitalism. New York: Pluto Press, 2009.

PESCE, B. A menina do vale: como o empreendedorismo pode mudar sua vida. São Paulo: Enkla, 2015a. . A sua melhor versão te leva além. São Paulo: Enkla, 2015 b.

PISTORI, M. H. C.; BANKS-LEITE, L. Argumentação e construção de conhecimento: uma abordagem bakhtiniana. Bakhtiniana, São Paulo, v. 1, n. 4, p. 129-144, 2. sem. 2010.

PRADO, J. L. A. Convocações biopolíticas dos dispositivos comunicacionais. São Paulo: Educ/Fapesp, 2013.

SCHUMPETER, J. Capitalism, socialism, and democracy. New York: Harper \& Bros, 1942.

SENNETT, R. A corrosão do caráter: consequências pessoais do trabalho no novo capitalismo. Rio de Janeiro: Record, 2007.

SILVA, F. A. A realidade que inspira. In Pesce, B. A menina do vale: como o empreendedorismo pode mudar sua vida. São Paulo: Enkla, 2015. p. 11-14

VAN DIJK, T. A. La ciencia del texto. Barcelona: Paidós, 1978.

\section{Sobre 0 autor}

Vander Casaqui - Professor do Programa de Pós-Graduação em Comunicação Social da Universidade Metodista de São Paulo. Doutor em Ciências da Comunicação pela Universidade de São Paulo, com Pós-Doutoramento pela Universidade Nova de Lisboa.

Data de submissão: 11/04/2019

Data de aceite: 15/12/2019 